\title{
Portfolios as a Strategy to Lower English Language Test Anxiety: The Case of Chile
}

\section{Amanda Contreras-Soto}

M.A.,Parroquial Santa Rosa de Lo Barnechea School, Chile, ama.contreras@gmail.com

\section{Mauricio Véliz-Campos}

Prof., Teaching and Learning, Universidad SEK, Chile, mauricio.veliz@usek.cl

\section{Leonardo Véliz}

PhD, Deakin University, Burwood-Australia, leonardo.v@deakin.edu.au

Language tests are widely used in education as the primary mode of assessing students' learning. These, however, more often than not, generate high levels of anxiety in students, which, in turn, obscures the observed learning behaviours. The present study aimed to determine whether or not 6th graders' levels of test anxiety could be reduced through the use of a writing portfolios strategy. Drawing on a mixed-methods approach, our study used one-group non-randomised pre- and posttest surveys along with a focus group interview. The pre-test survey was administered on 26 students in order to determine the initial levels of test anxiety. This was followed by a four-week writing portfolios intervention. Upon completion of the intervention procedure, the post-test survey was administered to find out the potential impact of the use of writing portfolios on the reduction of test anxiety levels. Through the use of descriptive statistics and a paired t-test, the test data revealed that writing portfolios contribute to the lowering of students' testrelated anxiety. Furthermore, the analysis of the focus group interview data showed that learners gained greater levels of confidence.

Keywords: test anxiety, portfolios, writing portfolios, assessment in EFL, language testing in Chile

\section{INTRODUCTION}

It has been widely admitted that tests, including language tests and other similar measures of language abilities, allow different stakeholders such as teachers, parents, administrators and prospective employers, to be certain that students are progressing towards "some generally accepted standard or have achieved a requisite level of competence in their second language" (Douglas, 2010, p. 1). Among several other 
features gleaned from the use of language tests, Bachman (2000) and Douglas (2010) point to the centrality of tests as public policy instruments, which roughly conforms to the notions of a technical-behavioural curriculum model (McKernan, 2008). One of the immediate implications of this is that high-stakes testing, as is the case of national examinations, is utilized to ensure that students at educational institutions are held to the same standards, which results in teachers' perceptions and conceptualizations of passing a test as the ultimate goal of the language learning process (Cheng, 2008).

In the realm of Teaching English to Speakers of Other Languages (TESOL), English language tests are used ubiquitously in a variety of forms and for different purposes. Hughes (1989), for instance, identifies four major kinds of tests which include proficiency tests, achievement tests, diagnostic tests, and placement tests. As far as the purposes of testing are concerned, Hughes also indicates that language tests are generally aimed at (i) measuring language proficiency; (ii) discovering how far students have achieved the objectives of a course; (iii) diagnosing students' language strengths and weaknesses; and (iv) assisting students' placement process.

Testing, as pointed out by O'Donnell (2017), is intended to positively contribute to the learning process; however, one of the unintended effects of testing is test-related anxiety, which often results in students' poor performance, and learners' low academic self-concept (Goetz, Preckel, Zeidner \& Schleyer, 2008), which in theoretical terms is precisely the opposite of what assessment is all about. However, a couple of central questions that arise here are, whether tests are effective measures of students' language abilities, and overall learning, and whether learners feel that language tests truly assess them on their ability to use the language. For some, a well-developed test can successfully evaluate someone's ability to use the language in a valid and reliable way, yet no matter how well a test is designed, learners' attitudes towards it usually revolve around anxiety and stress (Brown, 2007). Test related anxiety is a type of anxiety experienced by students in an assessment context. Its symptoms may vary among individuals, yet they are unpleasant and debilitating.

Alemi (2010) argues that "test anxiety can include performance anxiety and content anxiety" and that both make it hard for students to "concentrate on tests and perform adequately" (p. 47). Mueller (as cited in Brown 2007) also claims that tests upset learners and increase anxiety as they anticipate questions learners cannot answer. Moreover, tests also make them feel disappointed if they do not receive the expected grades. Notwithstanding the above, it must be pointed out that the use of tests is not necessarily wrong; however, people need to understand that they are not the only instruments that can be used to gather data about learners' learning. There are alternatives in assessment that provide teachers and learners with different perspectives on evaluation. Language meaning, language skills, declarative knowledge, all can be evaluated in more than one way. As a matter of fact, alternative assessment or alternatives in assessment can often incorporate real-world contexts and go beyond classroom boundaries, which, in turn, entails the need for students to perform and think more creatively. Brown (2003) posits that alternative assessment "comes with more useful feedback to students, the potential for intrinsic motivation, and ultimately a more complete description of a student's ability." (p. 14). 
Using alternatives in assessment should be a must in the twenty-first century classrooms. Traditionally, tests have been used to evaluate students' knowledge or competence, but with the passage of time we have learnt that different assessment procedures exist, and that they provide the learner with more meaningful opportunities for learning.

A writing portfolio is a collection of texts written by a student. It is a collection of documents which has been implemented as an alternative assessment tool in recent decades (Samad et al., 2015), which has become increasingly popular in language learning (Charvade et al., 2012). Thus, instead of giving information about what the learner knows, as an ordinary test would, the portfolio provides information that demonstrates what the learner can do with what he/she knows. To put differently, as Lam (2014) explains, a portfolio more "productively aligns the teaching and assessment" (p.710). Therefore, writing portfolios provides these students with greater opportunities to demonstrate what they know. Also, the use of portfolios engages learners in the production of authentic texts; thus, the learners are in charge of their learning process.

The present study features writing portfolios not only as an alternative way of assessment of EFL at a private school in Santiago, Chile, but most importantly, as a tool to lower learners' test-anxiety levels. Thus, in light of the fact that tests are capable of producing (relatively) high levels of anxiety in test-takers, and that portfolios can better engage learners, this investigation seeks to answer the following research questions:

1. In what ways can the use of writing portfolios potentially decrease $6^{\text {th }}$ graders' levels of test-related anxiety?

2. To what extent can the use of writing portfolios provide learners with confidence in their knowledge of the subject matter?

\section{Literature review}

\section{Language assessment and testing}

The term assessment can be used in different domains. For instance, people assess situations, such as a public presentation, by considering all the aspects comprising the presentation, namely, topic, speaker, audience, and their own prior knowledge on the topic or speaker, among others. Depending on our assessment of the situation we may need to employ different strategies. For example, if the speaker's tone of voice is too soft, we will have to pay better attention to body language. This study focuses on the educational use of the word assessment.

The definitions of assessment and testing can be easily confused or used interchangeably. For some, these terms represent two sides of the same coin (Leung \& Lewkowicz, 2006). "Assessment and evaluation are pervasive features of human activity: We evaluate everything and are being evaluated all the time. Education is no exception" (Erickson et al., 2014, p. 1). Testing, on the one hand, is a method used to gather "information to be used in making educational decisions" (Genesee \& Upshur, 1996, p. 140) and consists in the act of giving tests to measure someone's knowledge or ability, or the application of a measuring tool used in order to find out something, or determine whether something works or not. Assessment, on the other hand, is a much 
broader concept in that it also incorporates testing. According to Brown (2003) and Hughes (2003), (language) assessment is an ongoing process which teachers (consciously and subconsciously) engage in to assess or evaluate their learners' progress and/or their performance. Assessment occurs during class time and there is no starting or end time - as is the case with tests - because teachers listen to what the learners say, pay attention to how they say it, and immediately make "an assessment of the student's performance" (Brown, 2003, p. 4). Put differently, as Leung and Lewkowicz suggest, "in the educational measurement literature, assessment is a superordinate term for all forms of assessment, and testing is a term for one particular form of assessment" (2006, p. 212). Unlike measurement, which entails making use of a tool to determine how heavy, or long something is, assessment refers to the "application of a measuring tool to determine the degree to which educationally valuable knowledge, skills and other attributes have been, or are, being acquired" (Becker \& Shute, 2010, p. 4).

As per testing, the results of tests are provided in the form of a numerical score that can be interpreted in different forms. For teachers, a score can tell how much his/her students know; for learners, it might mean the same, or just a number. McNamara (2011) states that test scores can also be read as real-world skills or abilities. Therefore, it can be pointed out that test scores can define a person's future, especially high stakes tests. In this line of thought, McNamara (2000) also claims that tests are so powerful that they can determine the life of a test taker and influence the reputation of teachers and schools. Similarly, as Gysling (2016) argues that the Chilean state currently keeps complete control of education through testing. "The effect of tests on teaching and learning is known as test washback" (bold in original text) (McNamara, 2000, p. 73), and can be either beneficial or harmful, where the latter may correspond to test-related anxiety. In this respect, Hughes (2003) argues that test scores do not always reflect students' true abilities and are often of poor quality, "hav[ing] a harmful effect on teaching and learning, and fail[ing] to measure accurately whatever it is they are intended to measure." (2003, p. 1), which seems to provide justification for the incorporation of alternative procedures aimed to better measure learners' skills and knowledge.

\section{Test-related anxiety}

The exact relationship between test anxiety and language learners' achievement still remains somewhat terra incognita, despite the fact that Horwitz reported that feelings of anxiety seemed to have a negative impact on language learners' achievement/performance, as early as during the 1980s (Tanveer, 2007). Recent research has suggested that students suffering from test anxiety have problems with their working memory capacity (Shi, Gao \& Zhou, 2015) and with their social lives (Knoll, Valentiner \& Holzman, 2016).

Test anxiety results from the fear to fail on a test or insufficient command of the target language (Tanveer, 2007). Test anxiety corresponds to what Alemi and Birjandi, (2010) term debilitative anxiety, which often results in an increase of poor responses from the learners because they feel that the learning tasks are to be absconded, amidst evaluative situations and/or unfamiliar tasks on tests. Alemi and Birjandi, (ibid.) identify some of 
the possible reasons for test anxiety, where the first one is said to be linked to "lack of preparation as indicated by (a) cramming the night before the exam, (b) poor time management, (c) failure to organize text information, and (d) poor study habits" (p. 47).

Tanveer (2007) also calls for further investigation into designing and implementing mechanisms used to alleviate test anxiety in the classroom. In this respect, and aligned with the purpose of this study, Gwynne (2011) and Harms (2011) recommend writing about how you feel or about what makes you nervous in order to lower test anxiety, which in this investigation is partly achieved with the use of portfolios. Aside from having learners write about the way they feel when faced with school language tasks and tests, writing portfolios are used in this investigation to practice what has been taught in class through writing, which is expected to address one of the major cause of test anxiety, lack of preparation (Alemi \& Birjandi, 2010). In a meta-analysis of test-anxiety intervention studies carried out by Ergene (2003, as cited in Damer \& Melendres, 2011, p. 165), the author reports that some of the most successful interventions were those that incorporated skill-focused strategies with cognitive or behavioural approaches, for instance, test-taking skills training, combined with emotive therapy and relaxation training.

\section{Portfolios}

Portfolios have been used systematically in education - and English language learning environments - for the past few decades and are often understood as a collection of learners' academic work, used to inform about the students' progress or achievements (Brown \& Hudson, 1998; Genesee \& Upshur, 1996). In English language learning environments, portfolios have been used as alternative assessment procedures as they (i) allow teachers and learners to focus on the process as well as the product and (ii) combine "learning and assessment activities together" (Charvade et al., 2012).

Some recent studies have shown that the use of this alternative assessment is beneficial for students as it allows them to improve not only their writing ability but also other language sub-skills. Ghoorchaei et al. (2010) conducted a study aimed to determine the impact of portfolio assessment on Iranian EFL students' writing abilities and other subskills. The findings suggest that portfolio assessment positively affected students' overall writing achievement, as well as their focus, elaboration, organization and vocabulary. Similarly, Aydin (2010) examined 204 EFL Turkish students' perceptions on portfolio assessment. The results suggest that portfolios contributed to their vocabulary and grammar knowledge, and the development of reading, research, and writing skills.

The positive ramifications of the use of portfolios extend far beyond the obvious. Research has also demonstrated that portfolio assessment can empower students and facilitate self-regulated learning (Charvade et al., 2012; Lam, 2014; Mak \& Wong, 2017). Moreover, portfolios can be a suitable tool when providing written feedback since learners improve their writing skills based not only on the comments given by the teacher, but also on their own reflections (Atai \& Alipour, 2012). The only drawbacks of using writing portfolios are that (i) they are not feasible for large scale assessment; (ii) 
they may be excessively time consuming (Samad et al., 2015); and that there may be a good deal of bias from the assessor (Shavelson \& Klein, 2009).

Writing portfolios in this study are not meant to be used as a proper graded activity, or as an ordinary assessment procedure. The idea of using this alternative assessment procedure, as pointed out earlier, is to provide learners with the confidence they lack, and thus lower the expected levels of test anxiety. To the researchers' knowledge, no similar studies have been found dealing with how this alternative in assessment may help students reduce potential levels of anxiety experienced in testing situations.

\section{METHOD}

This study is framed by a mixed-methods approach, which allows for the combination of both quantitative and qualitative methods (Creswell, 2009). In this investigation, the positivist quantitative approach is present in the form of a quasi-experiment, more specifically a one-group non-randomised pre-test post-test survey design, followed by a focus group interview. No particular methodological priority is given to either type of data, although the potential depth of the qualitative data may take up more space and time as it can also more readily spark an interest in further related research. The rationale for the use of this research approach lies in the possibility to triangulate data sources (Creswell, ibid.), with a view to finding possible avenues of convergence and/or differences.

Due to the type of experiment, a quasi-experiment, at least two variables can be identified, namely, a dependent (anxiety levels) and an independent one (writing portfolios). Thus, the independent variable is expected to produce a certain change in the dependent one.

\section{The data-gathering instruments}

For the quantitative data, the pre- and post-test surveys used in this study draws upon an instrument first devised by Sarason in 1984, the Tests Anxiety Scale (TAS). Despite the fact that it is a relatively old instrument, it still enjoys much prestige amongst scholars as it is often cited in the relevant literature. The TAS has consistently evidenced test-retest validity in the .80 s for intervals of a few weeks with all of the survey items. Also, as Fernández-Ballesteros (2003) suggests, the survey validity becomes evident as it has shown to correlate positively with other test anxiety measures, as is the case of the strong correlation found between the TAS and the Test Anxiety Inventory (TAI) ( $r=.82)$ (Fernández-Ballesteros, 2003).

In order to answer the research questions of this study, the participants were asked to complete the pre- and post-test surveys in order to find any possible effect of the writing portfolios strategy (the treatment) on test anxiety levels over a period of time.

The survey was translated into Spanish in order not to compromise comprehension. Additionally, another TESOL professional from the school where this study took place proofread the translated version for the sake of validity. Moreover, the review of the survey also went through expert judgement validation and piloting. 
The instrument featured three different sections. The first one consisted of 31 items on a four-point Likert scale, where the participants indicated their extent of agreement (according to Dörnyei, 2007, p.105) with a statement. The coding system used was as follows: $1=$ Strongly disagree; $2=$ Disagree; $3=$ Agree; and $4=$ Strongly agree. (see sample item below).

Figure 1

Survey sample item, test-anxiety item.

1. Mientras tomo una prueba pienso que mis compañeros son más inteligentes que yo.

The survey was previously piloted in a different $6^{\text {th }}$ grade at the same school. As a result of the students being under similar conditions, it was expected that they would potentially encounter similar difficulties - if any at all. This would make it easier to identify if the survey items needed to be reworded or not. As a result of the piloting stage, some minor changes had to be made (compare Appendix A, form A [first survey design] with Appendix B, form B [final version], for the pre-test survey; the post-test survey remained the same [Appendix C], save for the questions dealing with perceived English proficiency). The participants completed the survey during class time and the piloting session was duly timed in order to ensure time-related reliability in the final application.

The second part of the survey included two open questions (items 32 and 33), while the third part contained three questions that did not provide information about test anxiety; they provided personal information about the learners and their relationship to EFL. Items 34, 35, and 36 were presented as multiple choice, wherein the learners had to choose only one option (see Appendix A).

\section{Focus group interview}

In order to capture learners' thoughts and feelings more thoroughly, a focus group interview was conducted with a small representative sample: from the totality of 26 students who completed the survey, seven participated in the focus group discussion, once the treatment and the post-test had taken place. Interviews enrich the data because, as Eder and Fingerson (2002) suggest, "it is difficult for any single method to capture fully the richness of human experience..." (p. 344) and because "participants build on each other's talk and discuss a wide(r) range of experiences and opinions" (p. 328). The orientating questions put to the participants dealt with how they felt during the writing portfolio activities and with whether the activities had helped them gain greater confidence levels.

\section{Writing portfolios intervention}

The treatment in this study was focused on writing portfolios and on how its systematic use could help reduce students' levels of test anxiety - if at all. To this end, the students were expected to take an English test, during week 1; during the following lesson, the students were asked to complete the survey for this investigation; later, a four-week 
period was planned to cover the contents of the corresponding unit of study, through a writing-of-portfolios treatment. Prior to the survey, each of the participants' parents was given a letter of consent as $6^{\text {th }}$ graders are minors. The letter of consent explained in their native language the purpose of the study, the importance of their participation, and confidentiality and freedom to volunteer to take the survey or withdraw from the study at any time. The coordinator of the school where the study took place was also sent a consent form.

Once the intervention had ended, the students took their unit test, followed by the second survey, used as a post-test survey. The entire process, including the administration of unit tests and surveys originally consisted of a six-week period.

During the time period between the pre- and the post-test survey administration, students were required to write paragraphs to practise what had been taught throughout the unit of study through writing. The students knew the purpose of the surveys and the intervention, so they were willing to participate actively in the writing of their portfolios.

The $6^{\text {th }}$ grade class where the intervention took place had English language lessons on Mondays (90 minutes), Wednesdays (45 minutes), and Thursdays (45 minutes). New content was introduced on Mondays; the new content was practised on Mondays and Wednesdays. On Thursdays, the students were asked to write a paragraph. The instructions were very simple: They were asked to use specific vocabulary of the unit, thus fostering the practice of the target grammar and vocabulary at the same time. Paragraphs had to be from seven to fifteen lines long including at least four out of eight words given by the one of the teacher researchers. Once they had finished writing, each student received individual feedback as they all approached the teacher's desk, and read the paragraph aloud together. The teacher indicated where corrections needed to be made, although some students realized them at the moment of reading.

The instructions for the writing task were similar on all occasions, yet the vocabulary and grammar points varied. With the passage of time, the students noticed they received fewer and fewer corrections.

The intervention was originally planned for a four-week period; however, due to unforeseen administrative disruptions, it ended up spanning seven weeks, during which time the students wrote a total of four pieces of writing for their portfolios.

Since the study focused on test-related anxiety and the treatment described above was meant to be used as a possible strategy to lower test-related anxiety levels, a brief mention needs to be made about the tests that students undertook. The instruments that were used to potentially cause test-related anxiety were the unit tests designed by the English teacher. For every unit of study, the students were evaluated. They took achievement tests that were specially designed to assess students' achievement (Hughes, 2003). The contents of the tests were directly connected to the language taught during a unit of study and only contained "what is thought that the students have actually encountered" (Hughes, 2003, p. 13). As far the unit tests go in particular, the first one was aimed at measuring the students' ability to use prepositions appropriately, to identify and describe items of clothing, and to provide personal information, with six 
different sections; two sections dealt with grammatical knowledge, two involved vocabulary, while the last two combined grammar, vocabulary, and writing (see Appendix D). The second test was aimed at measuring the students' ability to use cardinal numbers, some past forms, and to demonstrate reading comprehension. The test also comprised six sections, which deal with vocabulary, grammar, reading and writing combined (see Appendix E). The test specifications for both tests can be found in Appendices F and G.

A visual representation of the methods utilised in the data collection process is found in Figure 2.

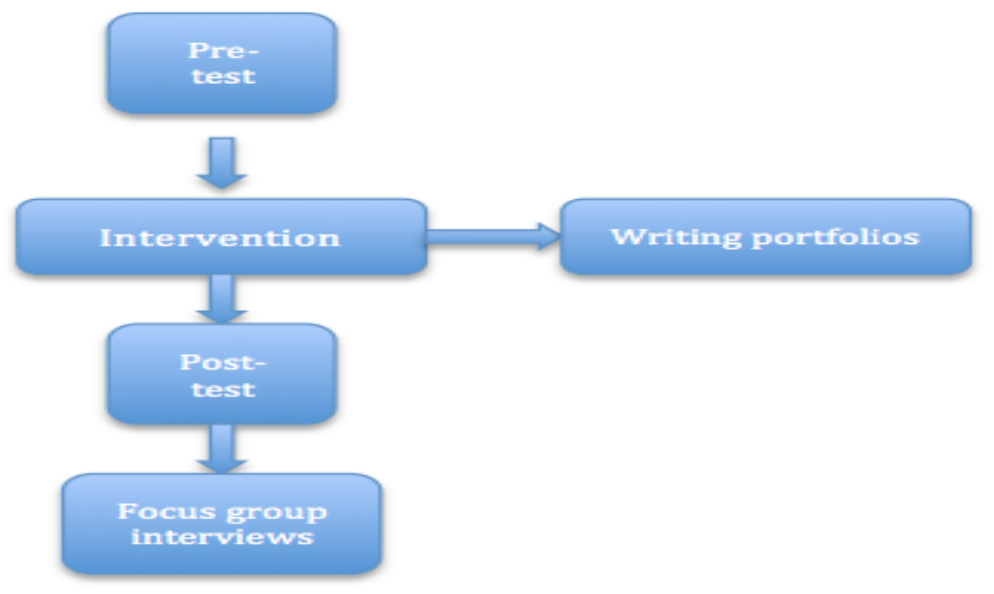

Figure 2

Methods utilized and procedures used.

The participants

A non-probabilistic, quota sampling procedure was used in this study. 26 students, out of a total of 32, agreed to participate voluntarily in the investigation. The participants made up a $6^{\text {th }}$ grade class taught by one of the teacher-researchers, from a catholic school in Santiago, Chile. The participants seemed interested in learning English and reported to have a fairly good level of English. Regarding the focus group interview, a representative sample of seven students expressed an interest in participating in the datagathering activity, which took place once the post-test had already been conducted.

\section{Data analyses}

The survey data were analysed using SPSS version 21, which yielded descriptive statistics, both measures of central tendency and measures of variability. Items 22 and 23 were reversed in the scoring coding process because of their wordings. Next, a paired $t$-test was used to determine whether the difference between the two sets of data stemming from the pre and post-test surveys were statistically significant. 
The analyses of the qualitative data from the focus group interview were conducted through a selective transcription process which attempted to focus on those language stretches that seemed more relevant to the purpose of this study. Content analysis was employed to find commonalities and thus make valid inferences from the data.

\section{FINDINGS}

The results are presented by research question. The first research question dealt with the impact that using writing portfolios had on 6th graders' levels of test-related anxiety. The mean for test-related anxiety in the first wave was 2.53 ( $\mathrm{SD}=.287$ ) while in the second wave it was 2.24 ( $\mathrm{SD}=1.484)$. For both variables, the Shapiro-Wilk test was nonsignificant, which suggests that these indicators have a normal distribution $(\mathrm{W}=.987, \mathrm{z}=-$ $2.208, \mathrm{p}=.986$, and $\mathrm{W}=.973, \mathrm{z}=-.630, \mathrm{p}=.736$, respectively). In order to assess the differences between both waves, a paired $t$-test was used. The results showed that after the intervention the decrease in test-related anxiety was significant, $\mathrm{t}(24)=3.945, \mathrm{p}<.001$. Indeed, Graph 1 shows the mean scores for the students' responses for both the pre and the post-test surveys.

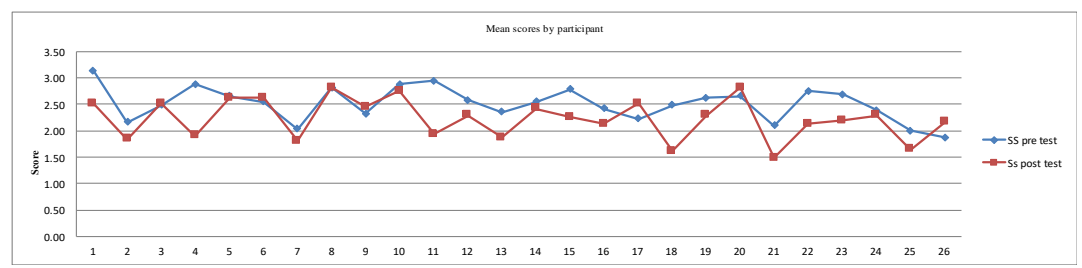

Graph 1

Participants' mean scores in pre and post-test anxiety surveys.

As can be observed, the levels of test anxiety decreased in the post-test survey in $73 \%$ of the participants. Out of 26 students that took both surveys and participated in the intervention, 19 present a lower level of test anxiety, 6 show an increase (23\%), and one student's score remained unchanged. Moreover, the mean score for the whole class, focused on students' anxiety levels, was 2.51 in the pre-test and 2.22 in the post-test, meaning that in the results from the second questionnaire, a drop of .29 can be seen. Not only did the mean score decline, but also the degree of dispersion was fairly lower in the post-test survey, which is to be interpreted as students' scores being grouped closer together. By isolating the group of participants whose test-related anxiety levels underwent a drop, it can be pointed out that the mean score was 2.54 in the pre-test and 2.10 in the post-test, indicating quite a dramatic drop of .44 .

While all items tap into the construct of anxiety, there are some that tap into it more directly than others. As a way of illustration, Item 1, while taking a test I think that my classmates are smarter than I am, does indeed convey the idea of a potentially debilitating feeling or thought, capable of having an impact on the learner's performance. Item 2, however, I sweat a good deal while taking a test, seems more explicit in conveying a symptomatic condition of anxiety. Graph 2 shows the behaviour of scores on the pre- and post-test. 


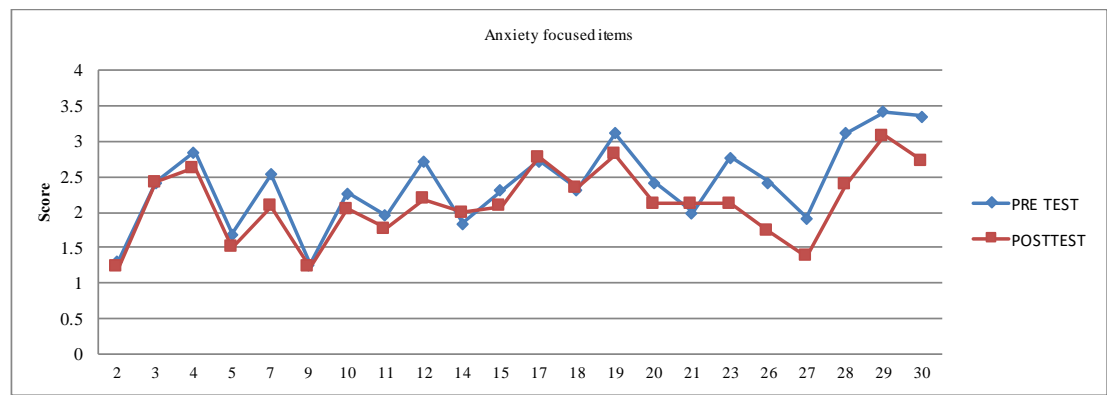

Graph 2

Mean scores for anxiety-focused items in pre- and post-test surveys.

From the graph it can be observed that from the 22 items, 17 present a lower mean score in the post-test, while only in 4 items the score is slightly higher in the post-test. Indeed, the drop observed in the items shown above appears considerable in that the mean score for the isolated items falls from 2.55 in the pre-test to 2.08 in the post-test.

The second research question deals with the perceived gains in confidence levels resulting from the writing portfolios activity. In this respect, 9 items from the questionnaire and the analysis of the qualitative data from the focus group interview contribute to answering the question. Graph 3 shows a drop in anxiety, where confidence levels increased as a result.

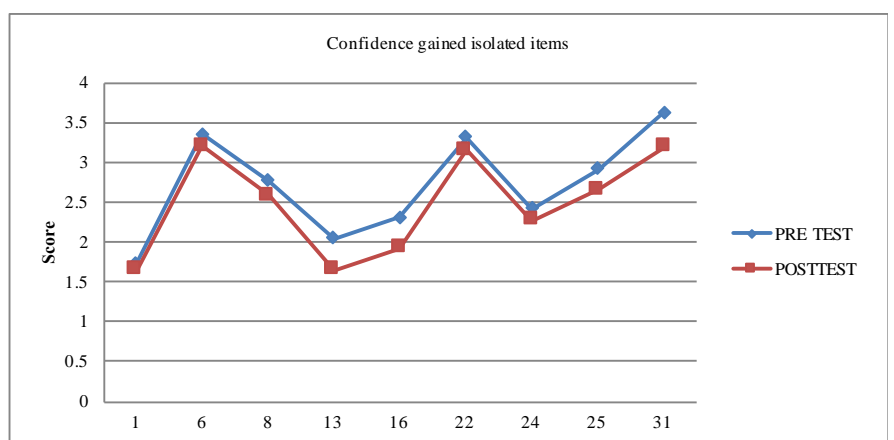

Graph 3

Mean scores for confidence-related items in pre- and post-test surveys.

As can be observed, the scores of all the isolated items are relatively lower in the posttest. In fact, the mean score for such items in the first questionnaire is 2.72 , while in the post-test it comes to 2.47 . The items that presented a more considerable fall were items 13,16 , and 31 , with a difference of $.39, .39$, and .43 , respectively.

During the focus group interview, the participants were asked to talk about (i) how they felt during the paragraph writing activity, (ii) whether they felt more confident, (iii) what they thought about working in pairs, (iv) error correction in the writing activity, and (v) and test anxiety. The analysis procedure yielded three categories, namely Confidence 
gained, Collaborative writing, and Error correction, as can be observed in the summary presented in Table 1 below. The category titled Confidence gained is the one that groups more comments at the expense of the other two. Overall, all the views dealing with confidence gained suggest that their interpretations of the process of writing were quite optimistic and assertive. As per Collaborative Writing, notwithstanding the small number of tokens, they, too, suggest a positive tone, save one student who seemed to be open to various forms of work. The third category, Error correction, shows comfort on the part of the learners who felt pleased with the procedure used; they added that learning from their own mistakes was something positive as well.

Table 1

Participants' comments according to categories

\begin{tabular}{|c|c|c|}
\hline Confidence Gained & Collaborative Writing & Error Correction \\
\hline $\begin{array}{l}\text { "I think that at the beginning there are words } \\
\text { that one thinks that will never find, but with } \\
\text { the passage of time, the paragraphs had more } \\
\text { content." }\end{array}$ & $\begin{array}{l}\text { "I had a lot of fun because we } \\
\text { used our imagination a lot and as } \\
\text { we had already written more } \\
\text { paragraphs, we knew more words } \\
\text { and added more things." } \\
\text { I prefer working in pairs } \\
\text { "because you help each other." }\end{array}$ & $\begin{array}{l}\text { "If you checked in general, } \\
\text { we wouldn't learn from } \\
\text { our mistakes. The } \\
\text { technique you use is very } \\
\text { good because everyone } \\
\text { checks their own mistakes, } \\
\text { not the others'." }\end{array}$ \\
\hline $\begin{array}{l}\text { "I was a lot less nervous. Before I was like } \\
\text { very nervous, but after the paragraphs I } \\
\text { improved. I mean, I calmed down. I felt more } \\
\text { confident for the test." }\end{array}$ & $\begin{array}{l}\text { "It was the same for me, to do it } \\
\text { alone or in pairs." }\end{array}$ & $\begin{array}{l}\text { "I think this project will be } \\
\text { useful for me because I } \\
\text { learn from my mistakes." }\end{array}$ \\
\hline $\begin{array}{l}\text { "I think that in the paragraphs we had to use } \\
\text { a lot from what we already know, so for the } \\
\text { test it wasn't so difficult because with the } \\
\text { paragraphs we already knew." } \\
\text { "Before, I didn't even finish the paragraphs } \\
\text { because I didn't know anything. But after I } \\
\text { studied for the paragraphs, I felt much better. } \\
\text { I could do more things." }\end{array}$ & $\begin{array}{l}\text { "I think that is more fun when } \\
\text { you do it in pairs, but when you } \\
\text { do it alone, you write faster." }\end{array}$ & $\begin{array}{l}\text { "I think that paragraph } \\
\text { writing will be very useful } \\
\text { to learn from our } \\
\text { mistakes." }\end{array}$ \\
\hline \multicolumn{3}{|l|}{$\begin{array}{l}\text { "With the paragraph activity I started to feel } \\
\text { better. I felt more calmed. }\end{array}$} \\
\hline $\begin{array}{l}\text { "I think it (writing portfolio) was better } \\
\text { the next test." }\end{array}$ & & \\
\hline
\end{tabular}

\section{DISCUSSION}

The present study was set out to examine writing portfolios as a possible device to lower learners' levels of test anxiety. As observed in the findings, after the intervention took place, students did report a significant drop in anxiety in testing situations as the quantitative results suggest. Nonetheless, and despite the encouraging figure, the question whether writing portfolios serves as test preparation or whether the sheer writing activity lowers test takers' anxiety levels remains open. Yet, as Damiani (2004) hints, it can be understood that by writing consistently, learners demonstrate what they have learned in terms of what they can do with what they have been taught. She also claims that "they practice skills that enhance learning and effective development of products" (p.129), indicating the possible relationship between writing portfolios and 
the decrease in test anxiety levels, whose range of dispersion is lower in the post-test, suggesting a stronger consensus.

It is interesting to note that out of the seven participants that took part in the focus group interview, where they all mentioned that they felt more confident and less anxious after writing the paragraphs, two of them reported increased levels of anxiety in the post-test. In this respect, Eder and Fingerson (2002) argue that in (focus) group interviews "children construct their meaning collectively with their peers" (p. 329) and in collaborative talk sequences adolescents "build upon each other's ideas." (p. 341). It can be inferred that both students did not necessarily feel the same way as their classmates, but might have felt the pressure to agree with them. Another possible explanation is that one or both participants actually felt less anxious and/or more confident but did not take the questionnaire seriously enough when they completed it. In both cases, it is important to bear in mind that this study dealt with young adolescents whose moods changed rapidly. Notwithstandingly, the statistical difference between the two sets of data was significant.

According to Sarason (1978), one way of coping with test anxiety is avoiding tense and problematic situations, such as failure. During the intervention, all the students were given personalized feedback and were able to see the progression in their own paragraphs. Put differently, by reducing the possibilities of failure, confidence levels increased and test anxiety levels dropped.

All in all, it can be inferred that the systematic use of writing portfolios can help reduce students' levels of test anxiety and boost test takers' confidence levels. Indeed, Salehi and Marefat (2014) suggest that teachers should strive to create an anxious-free environment in order to enhance self-confidence. This can be done by "encouraging students' involvement in classroom activities and creating a comfortable atmosphere" (ibid., p. 938). The scant dispersion observed both in the pre- and post-test suggests that the drop in test anxiety and the increase in confidence levels were quite homogeneous across the group of participants.

As far as the focus group is concerned, and as Table 1 summarises, there is evidence of the increase of the participants' confidence levels. For instance, student no. 13 claimed that she felt her paragraphs had richer content with the passage of time, even though she felt insecure at first. She reported that: I think that at the beginning there are words that one thinks that will never find, but with the passage of time, the paragraphs had more content. It's not so 'Tarzan' language. Student no. 21 stated that she even found the test easier because it incorporated expressions they had already learned. She also felt she could do more things and more confident about the writing task. Similarly, student no. 9 claimed that he used to feel more anxious and nervous before a test, but now feels better and calmer. He remarked that: With the paragraph activity I started to feel better. I felt calmer. Before this intervention, I felt stressed during a test, maybe I needed to study more, and after that, I felt calmer. These are just some of the remarks that were collected in the focus group interview which clearly suggest higher levels of confidence. At the moment of the interview they were at ease, and there was no pressure put on them as regards answering the questions. They seemed empowered by their own learning 
process and more confident about their skills in the language. In this respect, Park (2004) claims that writing portfolios provide "a greater sense of authority or ownership, in turn can increase learner motivation, since learners feel a greater personal stake in the work they produce" (p. 2).

The topic of collaborative work emerged from the interview. In this respect, 6 out of 7 participants remarked they preferred working in pairs while one student showed no preference. Collaborative work is important because learners interact and co-construct knowledge (Storch, 2005). Confidence in EFL can be built by oneself or by others. Storch (ibid.) claims that "collaborative writing may encourage a pooling of knowledge about language" (p. 154); therefore, it may foster students' skills in the language and subsequently encourage them to do more things - as stated by the participants themselves.

Error correction was a topic that was brought up for discussion by the researchers in the focus group interview. By and large, the participants appreciated the error correction technique that was employed. One of the researchers read though and checked each paragraph individually together with the students. Although providing this kind of feedback can be time consuming, the students valued it greatly. The relationship between error correction and confidence gains is that written error correction helps the learners locate their errors and review their writing; learners believe that the feedback provided is more useful for their learning (Corpuz, 2011). Accordingly, learning from their errors is a supportive way of reviewing their own writing in order to write better and ultimately feel more confident for the next evaluation. Chandler (2003) showed in her study that the students who received error correction on their writing skills did create more accurate texts. She adds that after 10 weeks of writing and receiving written error correction, the students significantly improved their writing skills. For teenagers, improvement can also take the form of increased confidence. As McIntyre and Gardner suggest (as cited in Harrison, 2006), when students perceive themselves as proficient language learners, they are more likely to experience confidence gains. In other words, by writing paragraphs weekly, by receiving fewer corrections, and by feeling capable, the learners' confidence in the subject increased. Certainly, tasks that foster communication and self-expression, as is the case of writing portfolios, may "offer students a different affective world", which is also helpful in the reduction of anxiety levels (Harrison, 2006).

\section{CONCLUSION}

Portfolios are often used as alternatives (to traditional tests) in assessment and provide more freedom for the teachers and for the students, for they provide learners with new opportunities to demonstrate what they know. They require students to create or produce; they use real world stimuli, and they tap into higher-thinking skills (Brown, 2003), although self-reflection and self-monitoring do not follow naturally from using this type of alternative assessment procedure (Lam, 2016). Writing portfolios are student-centered and make learners work collaboratively and in a holistic way (Genesee \& Upshur, 1996). With this study, it can be claimed that the use of writing portfolios over a period of time helps reduce the levels of test-related anxiety students of $6^{\text {th }}$ grade 
may present. In addition, the writing tasks provided the participants with more confidence in the use of English as a foreign language as the students felt they were in control of their learning process.

Some of the implications arising from this study are that teachers should assess learners in different ways other than traditional tests, thus providing the learners with more authentic language use (Brown, 2003). By assessing learners in different ways, they will also feel more challenged and engaged with the subject (Damiani, 2004). The results also suggest that by implementing learning activities as the one used in the treatment in this study, language learners are empowered and take greater responsibilities for their own learning process. Thus, they can become active agents in their learning process instead of just being recipients of knowledge.

One of the limitations of this study is the fact that the sample was rather small, which makes it difficult to generalize the results to other realities. Another limitation found in this study is that the period of time covered by the intervention was relatively short; it would be interesting to see the effects of writing portfolios over a longer period of time within an experimental design framework.

Further research is needed in this study in order to better understand the effects of the use of writing portfolios over a longer period of time, using a proper experimental design, and with a different age group. Accordingly, Genesee and Upshur (as cited in Park, 2004) suggest, portfolios stimulate student interaction with peers and student ownership in the learning process. This feeling of ownership is enhanced by the fact that the portfolio experience is not a brief presentation of writing.

Collaborative work should also be further studied for the reasons presented above and because learners that participated in this enquiry, showed great preference for working collaboratively in assessment procedures as stated in the open questions of the pre-test. In this respect, Storch (2005) suggests that the writing process should be approached collaboratively, which will allow for a sense of shared ownership.

\section{REFERENCES}

Alemi, M., \& Birjandi, P. (2010). The Impact of Test Anxiety on Test Performance Among Iranian EFL Learners. Broad Research in Artificial Intelligence and Neuroscience, 1 (4), 44-58.

Atai, M. R., \& Alipour, M. (2012). The Effect of the Combination of Small-Group Conferencing and Portfolio Procedure on EFL Students' Writing Accuracy. Innovation in Language Learning and Teaching, 6 (2), 97-112.

Aydin, S. (2010). EFL Writers' Perceptions of Portfolio Keeping. Assessing Writing, 15 (3), 194-203.

Bachman, L. (2000). Modern Language Testing at the Turn of the Century: Assuring that What We Count Counts. Language Testing, 17 (1), 1-42. 
Bailey, A. L., \& Heritage, M. (2014). The Role of Language Learning Progressions in Improved Instruction and Assessment of English Language Learners. TESOL Quarterly, 48 (3), 480-506.

Becker, B. J., \& Shute, V. J. (2010). Prelude: Assessment for the 21st century. In B. J. Becker, V. J. Shute. (eds.), Innovative assessment for the 21st century. (pp. 1-11). New York, NY: Springer. Brown.

J. D., \& Hudson, T. (1998). The Alternatives in Language Assessment. TESOL Quarterly, 32 (4), 653-675.

Brown, H. D. (2003). Language assessment: Principles and classroom practices. San Francisco, CA: Pearson ESL.

Brown, H. D. (2007). Principles of language learning and teaching. New York: Longman.

Chandler, J. (2003). The Efficacy of Various Kinds of Error Feedback for Improvement in the Accuracy and Fluency of L2 Student Writing. Journal of Second Language Writing, 12, 267-296.

Charvade, M. R., Jahandar, S., \& Khodabandehlou, M. (2012). The Impact of Portfolio Assessment on EFL Learners' Reading Comprehension Ability. English Language Teaching, 5 (7), 129-139.

Cheng, L. (2008). The Key to Success: English Language Testing in China. Language Testing, 25 (1), 15-37.

Corpuz, V. A. (2011). Error correction in second language writing: Teachers' beliefs, practices, and students' preferences. (Unpublished Master's dissertation). Brisbane: Queensland University of Technology.

Creswell, J. W. (2014). Research design: Qualitative, quantitative, and mixed approaches. California: Sage Publications.

Damer, E. D., \& Melendres, L. T. (2011). Tackling Test Anxiety: A Group for College Students. The Journal for Specialists in Group Work, 36 (3), 163-177.

Damiani, V. B. (2004). Portfolio assessment in the classroom. In A. S. Canter, L. Z. Paige, M. D. Roth, I. Romero \& S.A. Carroll (eds.), Helping children at home and school II: Handouts for families and educators (pp. 129-131). Bethesda, MD: NASP Publications.

Dörnyei, Z. (2007). Research methods in applied linguistics: Quantitative, qualitative, and mixed methodologies. Oxford: Oxford University Press.

Douglas, D. (2010). Understanding language testing. New York: Routledge.

Eder, D., \& Fingerson, L. (2002). Interviewing children and adolescents. In J. Gubrium \& J. Holstein (eds.), Handbook of interview research: Context and method (pp. 327347). California: Sage Publications, Inc. 
Erickson, G., Figueras, N., \& Takala, S. (2013). International assessments. In A. J. Kunnan (ed.), The Companion to Language Assessment: Abilities, context, and learners (pp. 285-302). Malden, MA: Wiley-Blackwell.

Fernández-Ballesteros, R. (2003). Encyclopedia of psychological assessment. London: Sage.

Flores, S. M., Batalova, J., \& Fix, M. (2012). The educational trajectories of English language learners in Texas. Washington, DC: The Migration Policy Institute.

Genesee, F., Upshur, J. (1996). Classroom-based evaluation in second language education. New York: Cambridge University Press.

Ghoorchaei, B., Tavakoli, M., \& Ansari, D. N. (2010). The Impact of Portfolio Assessment on Iranian EFL Students' Essay Writing: A process-oriented approach. GEMA Online ${ }^{\circledR}$ Journal of Language Studies, 10 (3), 35-51.

Goetz, T., Preckel, F., Zeidner, M., \& Schleyer, E. (2008). Big Fish in Big Ponds: A Multilevel Analysis of Test Anxiety and Achievement in Special Gifted Classes. Anxiety, Stress, \& Coping, 2, 185-198.

Gwynne, P. (2011). The write way to reduce test anxiety. U.S. News. Retrieved from http://www.usnews.com/science/articles/2011/01/14/the-write-way-to-reduce-testanxiety.

Gysling, J. (2016). The Historical Development of Educational Assessment in Chile: 1810-2014. Assessment in Education: Principles, Policy \& Practice, 23 (1), 8-25.

Harms, W. (2011). Writing about worries eases anxiety and improves test performance. U Chicago News. Retrieved from http://news.uchicago.edu/article/2011/01/13/writingabout-worries-eases-anxiety-and-improves-test-performance

Harrison, M. E. (2006). EFL writing anxiety: An examination of recent quantitative research. Unpublished Master's dissertation: Indiana University of Pennsylvania: Pennsylvania.

Hughes, A. (1989). Testing for language teachers. Cambridge: Cambridge University Press.

Hughes, A. (2003). Testing for language teachers. Cambridge, UK: Cambridge University Press.

Knoll, R., W., Valentiner, D. P., \& Holzman, J. B. (2016). Development and Initial Test of the Safety Behaviors in Test Anxiety Questionnaire. Assessment, 1-10.

Lam, R. (2014). Promoting Self-regulated Learning Through Portfolio Assessment: Testimony and rRcommendations. Assessment \& Evaluation in Higher Education, 39 (6), 699-714.

Leung, C., \& Lewkowicz, J. (2006). Expanding Horizons and Unresolved Conundrums: Language Testing and Assessment. TESOL Quarterly, 40 (1), 211-234. 
Mak, P., \& Wong, K. M. (2017). Self-regulation Through Portfolio Assessment in Writing Classrooms. ELT Journal, 72 (1), 49-61.

McKernan, J. (2008). Curriculum and Imagination: Process Theory, Pedagogy and Action Research. London: Routledge

McNamara, T. (2000). Language Testing. Oxford: Oxford University Press.

McNamara, T. (2011) Managing Learning: Authority and Language Assessment. Language Teaching,44 (4), 500-515.

O’Donnell, P. S. (2017). Executive Functioning Profiles and Test Anxiety in College Students. Journal of Psychoeducational Assessment, 35 (5), 447-459.

Park, T. (2004). An overview of portfolio-based writing assessment. Teachers College, Columbia University (Working Papers in TESOL \& Applied Linguistics No. 2). Retrieved from http://www.tc.columbia.edu/academic/tesol/WJFiles/pdf/TaejoonParkForum.pdf

Salehi, M., \& Marefat, F. (2014). The effects of foreign language anxiety and test anxiety on foreign language test performance. Theory and Practice in Language Studies, 4/5, 931-940.

Samad, A. A., Hussin, H., \& Sulaiman, T. (2015). Developing a Portfolio Assessment Model for the Teaching and Learning of English in Malaysian L2 classroom. English Language Teaching, 8 (7), 164-173.

Sarason, I., G. (1978). The test anxiety scale: Concept and research. In I.G. Sarason \& C.D. Spielberg (eds.), Stress and anxiety (pp. 193-216). Washington, DC: Hemisphere.

Sarason, I. G. (1984). Stress, Anxiety, and Cognitive Interference: Reactions to Tests. Journal of Personality and Social Psychology, 48 (4), 929-938.

Shavelson, R. J., \& Klein, S. (2009). The limitations of portfolios. Retrieved from https://www.insidehighered.com/views/2009/10/16/shavelson

Shi, Z., Gao, X., \& Zhou, R. (2015). Frontal Theta Activity During Working Memory in Test Anxiety. NeuroReport: For Rapid Communication of Neuroscience Research, 26, 228-232.

Storch, N. (2005). Collaborative Writing: Product Process, and Students' Reflections. Journal of Second Language Writing, 14, 153-173.

Tanveer, M. (2007). Investigation of the factors that cause language anxiety for ESL/EFL learners in learning speaking skills and the influence it casts on communication in the target language. Unpublished Master's dissertation. Glasgow: University of Glasgow.

Troudi, S., Coombe, C., \& Al-hamliy, M. (2009). EFL Teachers' Views of English Language Assessment in Higher Education in the United Arab Emirates and Kuwait. TESOL Quarterly, 43 (3), 546-555. 